\title{
Avaliação da concentração de substâncias reativas ao ácido tiobarbitúrico (TBARS) de ovelhas Dorper durante a gestação, desde o momento da concepção até 48 horas pós-parto: comparação entre gestação única e gemelar - resultados parciais
}

Bianca Paola Santarosa ${ }^{[a]]^{*}}$, Gabriela Nascimento Dantas ${ }^{[a]}$,Eduardo Klöppe ${ }^{[b]}$, Yuri Karen Sinzato $0^{[b]}$, Débora Cristina Damasceno[b], Danilo Otávio Laurenti Ferreira[ ${ }^{[c]}$, Andreza Amaral da Silva ${ }^{[d]}$, Roberto Calderon Gonçalves ${ }^{[a]}$

\footnotetext{
[a] Departamento de Clínica Veterinária, Faculdade de Medicina Veterinária e Zootecnia, Universidade Estadual Paulista (UNESP), Botucatu, SP, Brasil

${ }^{[b]}$ Laboratório Experimental de Ginecologia e Obstetrícia, Faculdade de Medicina de Botucatu, Universidade Estadual Paulista (UNESP), Botucatu, SP, Brasil

[c] Coordenadoria de Assistência Técnica Integral (CATI), Secretaria da Agricultura e Abastecimento (SAA) do Estado de São Paulo, Casa da Agricultura de Agudos, Agudos, SP, Brasil

[d] Departamento de Medicina e Cirurgia, Universidade Federal Rural do Rio de Janeiro (UFRRJ), Seropédica, RJ, Brasil
}

*Autor correspondente

e-mail: biancasantarosavet@gmail.com

\section{Resumo}

Aumento dos marcadores de estresse oxidativo, como as substâncias reativas ao ácido tiobarbitúrico (TBARS), foram descritos em vacas com cetose subclínica e ovelhas com toxemia da prenhez (TP). 0 objetivo deste trabalho foi comparar a concentração de TBARS em ovelhas, a fim de verificar o comportamento desta variável em animais gestantes de feto único e gemelar, bem como relacionar com a incidência de TP. Para isso, foram utilizadas 30 ovelhas da raça Dorper, criadas sob manejo semi-intensivo, hígidas, de 2 a 5 anos de idade, peso médio de $60 \mathrm{~kg}$. Constituíram-se dois grupos experimentais com 15 ovelhas cada: Grupo I (GI) - gestação de feto único, Grupo II (GII) - gemelar. Os momentos experimentais foram definidos como: MM (controle - imediatamente após inseminação artificial em tempo fixo), MG30 (30 dias de gestação), MG90 (90 dias), MG120 (120 dias), MG130 (130 dias), MG140 (140 dias), MP (parto), MPP1 (24 horas pós-parto), MPP2 (48 horas pós-parto). Colheram-se amostras de sangue por punção da veia jugular, em tubos de heparina sódica a vácuo, e foram mantidas em isopor com gelo até o processamento para obtenção de hemácias lavadas, que ficaram estocadas a - $80{ }^{\circ} \mathrm{C}$. As amostras foram descongeladas e analisadas em uma única vez. Foram realizados os ensaios para determinação de TBARS pela absorbância em espectrofotômetro de leitura em microplaca (Biotek ${ }^{\circledR}$ Power Wave XS) com comprimento de onda de 535 $\mathrm{nm}$. Os resultados foram expressos em nanomol/L de malondialdeído (MDA) por grama de hemoglobina 
(nM/g Hb). Para análise estatística dos dados, utilizou-se o programa Instat 3. Para verificar diferença entre os grupos foi usado o Teste T, e entre os momentos, empregou-se a análise de variância (ANOVA) seguida de teste de comparações múltiplas de Tukey. Observou-se diferença estatística $(\mathrm{P}<0,05)$ entre os grupos nos momentos MG30 (GI: 102,58 \pm 109,60 nM/Hb; GII: 33,07 $\pm 16,21 \mathrm{nM} / \mathrm{Hb} ; \mathrm{p}=0,0218$ ), MG140 (GI: $62,47 \pm 46,89 \mathrm{nM} / \mathrm{Hb}$; GII: 35,16 $\pm 19,25 \mathrm{nM} / \mathrm{Hb} ; \mathrm{p}=0,0461$ ) e MP (GI: 62,26 $\pm 46,98 \mathrm{nM} / \mathrm{Hb}$; GII: 32,40 \pm $19,67 \mathrm{nM} / \mathrm{Hb} ; \mathrm{p}=0,031$ ). Ao longo dos momentos houve diferença apenas no GII, sendo que os valores de TBARS no MG30 diferiram do MG120 e MG130; os resultados obtidos no MG120 foram diferentes de MG140 e MP; e por último, MG130 foi distinto de MP48. Nenhuma ovelha apresentou manifestação clínica de TP. Os valores da concentração de TBARS foram maiores nas ovelhas do GI. Apesar disso, nas ovelhas do GII houve diferença entre os momentos, o que mostrou oscilação da lipoperoxidação. Esse fato ocorreu devido ao maior gasto energético e exigência metabólica, que aconteceu nos animais do GII ao longo da gestação, principalmente no terço final, quando há maior desenvolvimento fetal. Marcadores de estresse oxidativo podem auxiliar na predição da TP. 0 diagnóstico precoce desta enfermidade pode evitar a morte da matriz e seus produtos, o que minimiza prejuízos econômicos e genéticos.

Agradecimentos: Fundação de Amparo à Pesquisa do Estado de São Paulo (FAPESP) - Processo FAPESP 2015/08714-8 e Fazenda Monjolão - Cabanha Araí \& Zumbi - Pardinho-SP. 